\title{
Effects of Different Light Qualities--LED on Apple Root-Stock JM7 Tissue Culture Seedling
}

\author{
Wenjing Huang, Guangzhu Yang, Fan Li, Liping Zheng, Jun Ma
}

Horticultural Institute of Yunnan Academy of Agricultural Science, Kunming, China

\section{Email address:}

angela_56@163.com (Wenjing Huang)

\section{To cite this article:}

Wenjing Huang, Guangzhu Yang, Fan Li, Liping Zheng, Jun Ma. Effects of Different Light Qualities--LED on Apple Root-Stock JM7 Tissue Culture Seedling. American Journal of Plant Biology. Vol. 3, No. 2, 2018, pp. 17-20. doi: 10.11648/j.ajpb.20180302.11

Received: August 22, 2018; Accepted: September 12, 2018; Published: October 10, 2018

\begin{abstract}
Used apple root-stock JM7 stem-tips as material to study different LED influence of different stages of tissue culture. The results showed that in the culture medium (bud induction medium $\mathrm{LS}+4.0 \mathrm{mg} / \mathrm{L} 6-\mathrm{BA}+0.2 \mathrm{mg} / \mathrm{L}$ NAA, proliferation medium $\mathrm{LS}+2.5 \mathrm{mg} / \mathrm{L} 6-\mathrm{BA}+0.1 \mathrm{mg} / \mathrm{L} \mathrm{NAA}$, rooting medium $1 / 2 \mathrm{LS}+0.5 \mathrm{mg} / \mathrm{L} \mathrm{NAA}+1.0 \mathrm{mg} / \mathrm{L} \mathrm{IAA}$ ), with $30 \mathrm{~g} / \mathrm{L}$ sugar and $9 \mathrm{~g} / \mathrm{L}$ agar, $\mathrm{pH} 5.8$, autoclave $121^{\circ} \mathrm{C}, 20$ minuets. At the same culture conditions, $21 \pm 1^{\circ} \mathrm{C}$ temperature, 12 hours of light, 12 hours of dark and same illumination time. The LED treatments were better than the fluorescent light of the germination; LED r $/ \mathrm{b}$ ratio 5:5, was the best on germination effect, the height of seedling was $1.84 \mathrm{~cm}$ and 10 leaves on 50 days of cultivation; LED r $/ \mathrm{b}$ ratio $6: 4$, was the best on the proliferation stage and rooting effect stage, the height of seedling was $4.15 \mathrm{~cm}$ on 45 days of proliferation and the main-root length was $5.97 \mathrm{~cm}$, and the height of seedling was $6.38 \mathrm{~cm}$ on 45 days of rooting stage; followed by LED r/b 7:3 and 5:5. In conclusion LED treatments were advantageous to the germination, seedling differentiation and rooting of apple root-stock JM7 tissue culture, better than fluorescent lamp group. It could get more quantities and stronger plants in the same culture conditions, also saved the culture time. LED was cold light source, it could produce less excess heat and truly reflects the feature of power-saving effectively. So it was reduced of the tissue culture production in a certain extent.
\end{abstract}

Keywords: LED Apple Root-Stock Tissue Culture Seedling Growth and Development

\section{Introduction}

"JM7"had been introduced to China for more than 15 years as apple root-stock. It had been bred by the Japanese national Apple research center, the parents were Malus prunifolia var. ringo and M9. After years of screening of the hybrid off spring, it was good at the disease, insect resistance, compatibility of varieties and adaptability to different environment, so it used widely now in Yunnan province.

Plant tissue culture referred to the process of cloning plant organs, tissues, cells and protoplast, put them under the aseptic conditions and the culture medium on artificial configuration to make them grow, differentiate and grow into a complete plant. The theory was based on the theory of cellular totipotency. It could be applied to rapid propagation of plants, virus-free, cultivation of new varieties, haploid breeding, germplasm conservation and genetic transformation. Tissue culture technology could achieve rapidly and larger breeding of seedlings in the short term. Rapid propagation of strawberry, citrus, orchid, carnation, clematis, rhododendron, rose and eucalyptus had been commercialized in many countries. Sugarcane, rose, chrysanthemum, seedless watermelon, oak, hawthorn, kiwifruit and cedar had been successful in China. The rapid propagation of apple root-stock by tissue culture method had achieved successful in many varieties [1-4], for example, G256, M9, Malus rockii Rehder, Zhongzhen, Qinzhen, Malus Teli and so on.

Light was one of the essential elements of plant growth, and the key of yield and quality. In tissue culture whole process just used the fluorescent lamp as light source before, but the fluorescent tube was easy to liable heat and damage. So the fluorescent lamp occupied $10 \%-20 \%$ costs in whole plant tissue culture process. LED was a new generation of semiconductor solid-state cold light source. LED technology was currently widely used in urban lighting, LED screen, automotive lighting and other aspects, now gradually played an important role in the production of agricultural seedlings. In the future, it will use in the airborne dimming technology, food analysis and in the arctic circle vegetable cultivation use the LED lights with hydroponics technology. 
LED technology was used quickly in the facilities horticultural industry, plant tissue culture, seedling breeding and plant production year by year [5]. Now, it was reported that the effects of LED light on the growth and development of horticultural crops were mainly concentrated on the vegetables and flowers, and there were few reports on fruit seedlings.

In this experiment, it studied the effect of different light quality (LED) on the growth of "JM7" tissue culture seedlings. Hope to understand: was LED light better or not in the tissue culture of woody plant (apple root-stock)? Were the breeding efficiency and quality better or not in LED light? Did the production cost and energy saved?

\section{Experimental Treatment and Methods}

\subsection{Germination Induction}

To get the branches with stem-tips of "JM7"from the cutting orchard of Horticultural Institute of Yunnan Academy of Agricultural Science in Kunming. The branches were sterilized by alcohol for $30 \mathrm{~s}$, washed 2-3 times by sterile water, then immersion disinfection in 20\% sodium hypochondria added with 1-2 drops of Twain 40 sterilized for 10 minutes, and washed 4-5 times by sterile water, then got the stem-tips, the different big and small stem-tips were vaccinated to the induced medium LS + $4.0 \mathrm{mg} / \mathrm{L} 6-\mathrm{BA}+0.2 \mathrm{mg} / \mathrm{L}$ NAA. Then put them under fluorescent lamp and LED red / LED blue light combination light source respectively. (LED red/blue light 5:5, 4:6, 3:7, 6:4, 7:3). Each bottle was inoculated with 4 stem-tips, 10 bottles for each treatment and cultured under the same temperature. To investigate the time of $50 \%$ germination, the germination rate, seedling growth, development for 35 days and the seedling growth on the 50th day. At the same culture conditions, $21 \pm 1^{\circ} \mathrm{C}$ temperature and 12 hours light, 12 hours dark.

\subsection{Proliferation and Differentiation Culture}

When the seedlings were $1-2 \mathrm{~cm}$ high, cut and transferred them to the proliferation and differentiation medium, $\mathrm{LS}+2.5 \mathrm{mg} / \mathrm{L}$ $6-\mathrm{BA}+0.1 \mathrm{mg} / \mathrm{L} \mathrm{NAA}$, inoculated 4 seedlings for one bottle, 5 bottles for each treatment and 1 repetitions. To investigate the seedling growth, development and multiplication coefficient on 30 days $\quad 40$ days and 50 days (multiplication coefficient $=$ The total number of new seedlings obtained from 1 successive generations/the original seedling number)

\subsection{Rooting Culture}

To cut the seedlings when the height more than $2.5 \mathrm{~cm}$ and transferred them to the root culture medium $1 / 2 \mathrm{LS}+0.5 \mathrm{mg} / \mathrm{L}$ $\mathrm{NAA}+1.0 \mathrm{mg} / \mathrm{L}$ IAA, inoculated 5 seedlings for one bottle, 5 bottles for each treatment and 1 repetitions. To investigate the rooting time of $50 \%$ seedlings, the average rooting rate, the root growth situation and seedling growth situation on 50 days.

\section{Results and Analysis}

\subsection{Effects of Different Light Quality on the Germination of Apple Root-Stock 'JM7'}

At the same culture conditions, $21 \pm 1^{\circ} \mathrm{C}$ temperature and 12 hours light, 12 hours dark. It can be known from Table 1 that the time of $50 \%$ germination was 8-10 days earlier by LED light source than the fluorescent light source, among them, LED red /LED blue 5:5, 6:4 groups were earlier 10-15 days, ahead of schedule. On the 50 days, the germination rate of LED light source all reached 100\%, 10\% higher than the fluorescent lamp treatment. On the 30 days and 50 days, the diameter of seedling height and true leaf diameter of LED treatments were significantly larger than the fluorescent lamp treatment. Among them, LED red/LED blue 5:5, 6:4 treatments were significantly greater than other treatments. The height of the seedlings was $1.33 \mathrm{~cm}, 1.42 \mathrm{~cm}$ and $1.68 \mathrm{~cm}$, $1.85 \mathrm{~cm}$, the number of true leaves were 6,6 and 11,10 . These two treatments were the best of all.

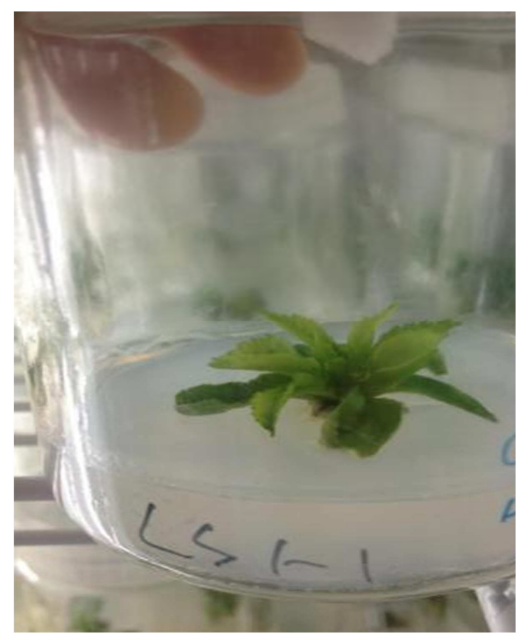

Figure 1. The germination of " $J M 7$ ”.

Table 1. Germination of "JM7" treated with different light quality.

\begin{tabular}{|c|c|c|c|c|c|c|}
\hline \multirow{2}{*}{$\begin{array}{l}\text { Grouping } \\
\text { experiment }\end{array}$} & \multirow{2}{*}{$\begin{array}{l}\text { The time of } 50 \% \\
\text { emergence seedlings (d) }\end{array}$} & \multirow{2}{*}{$\begin{array}{l}\text { The germination } \\
\text { rate of } 50 \text { days }(\%)\end{array}$} & \multicolumn{2}{|c|}{30 days of cultivation } & \multicolumn{2}{|c|}{50 days of cultivation } \\
\hline & & & $\begin{array}{l}\text { Seedling height } \\
(\mathrm{cm})\end{array}$ & $\begin{array}{l}\text { Number of true } \\
\text { leaves }\end{array}$ & $\begin{array}{l}\text { Seedling height } \\
(\mathrm{cm})\end{array}$ & $\begin{array}{l}\text { Number of true } \\
\text { leaves }\end{array}$ \\
\hline Fluorescent lamp & 40 & 90 & 0.85 & 2 & 1.10 & 6 \\
\hline LED r/b $5: 5$ & 25 & 100 & 1.33 & 6 & 1.68 & 11 \\
\hline LED r/b 4: 6 & 28 & 100 & 1.12 & 4 & 1.47 & 9 \\
\hline LED r/b 3: 7 & 28 & 100 & 1.09 & 3 & 1.39 & 9 \\
\hline LED r/b 6: 4 & 25 & 100 & 1.42 & 6 & 1.85 & 10 \\
\hline
\end{tabular}




\subsection{Effects of Different Light Quality on Proliferation and Differentiation of "JM7"}

According to Table 2, at the stage of seedling multiplication and differentiation, the multiplication factor of LED treatments were $0.5-1.7 \mathrm{~cm}$ higher than the fluorescent lamp treatment. Among them, LED r/b 6:4, 5:5, 7:3, the multiplication factor were all above 5.5. On 25 days, 35 days and 45 days, the seedlings height of LED treatments were higher than fluorescent lamp treatment. Among them, LED r/b $6: 4$ the seedling height were significantly greater than other treatments, they were $2.12 \mathrm{~cm}, 3.14 \mathrm{~cm}, 4.15 \mathrm{~cm}$. Followed by the LED $\mathrm{r} / \mathrm{b} 5: 5,7: 3$ treatments, the height of seedlings were $1.98 \mathrm{~cm} 、 2.69 \mathrm{~cm} 、 3.68 \mathrm{~cm}$ and $1.85 \mathrm{~cm} 、 2.52 \mathrm{~cm} 、 3.52 \mathrm{~cm}$. The fluorescent lamp treatment was $1.01 \mathrm{~cm}, 1.95 \mathrm{~cm}, 2.65 \mathrm{~cm}$. It can be known that the LED treatments were better than the fluorescent lamp treatment in the growth and development of apple root-stock "JM7"seedlings at the stage of proliferation and differentiation. And the best treatment was LED r/b 6:4, followed by LED r/b 5:5, 7:3 treatment.

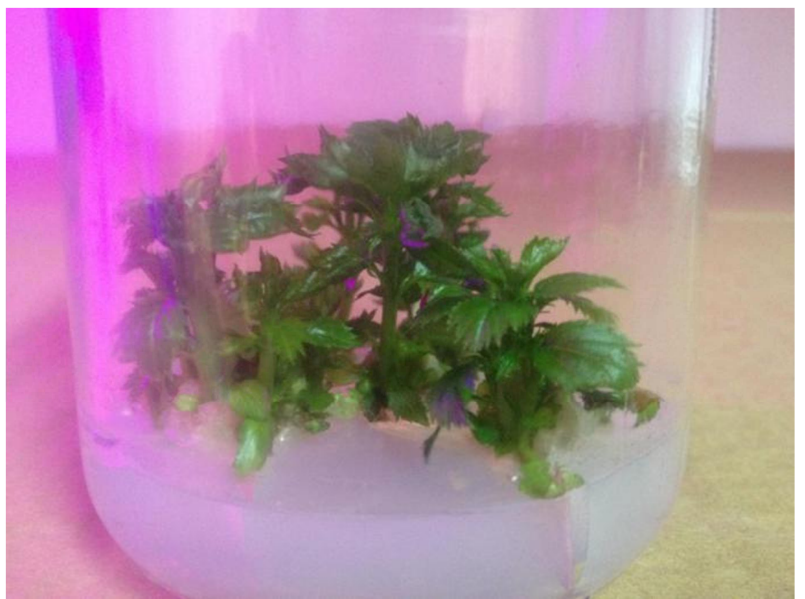

Figure 2. The proliferation and differentiation on LED $r / b 6: 4$.

Table 2. Proliferation and differentiation of "JM7" treated with different light quality.

\begin{tabular}{lllll}
\hline \multirow{2}{*}{ Grouping experiment } & \multirow{2}{*}{ Multiplication factor } & $\mathbf{2 5}$ days & 35 days & 45 days \\
\cline { 3 - 5 } & & Seedling height(cm) & Seedling height(cm) & Seedling height(cm) \\
\hline Fluorescent lamp & 4.5 & 1.25 & 1.95 & 2.65 \\
LED r/b 5: 5 & 5.8 & 1.98 & 2.69 & 3.68 \\
LED r/b 4: 6 & 5.1 & 1.66 & 2.25 & 3.47 \\
LED r/b 3: 7 & 5.0 & 1.52 & 2.20 & 3.35 \\
LED r/b 6: 4 & 6.2 & 2.12 & 3.14 & 4.15 \\
LED r/b 7: 3 & 5.5 & 1.85 & 2.52 & 3.52 \\
\hline
\end{tabular}

\subsection{Effects of Different Light Quality on Rooting of"JM7"}

According to Table 3, at the rooting stage of tissue culture seedlings of "JM7", the rooting time of LED treatments were 12-17 days earlier than fluorescent lamp treatment of $50 \%$ seedlings processing. Among them, LED r/b 6:4, 7:3 treatments were earlier 14 days. On 45 days, rooting rate of LED treatments were $25 \%$ more than the fluorescent lamp treatment. The average rooting rate of LED light combination all reached $100 \%$ and the root growth potential were stronger. Among them, LED r/b 6:4, 7:3 were the best, the main root length were $5.97 \mathrm{~cm}, 5.81 \mathrm{~cm}$. Followed by LED r/b 5:5, 4:6, $3: 7$ and the fluorescence treatment. The seedling height were $6.38 \mathrm{~cm}, 6.14 \mathrm{~cm}$ of LED $\mathrm{r} / \mathrm{b} 6: 4,7: 3$, they were higher than other treatments, followed by LED $\mathrm{r} / \mathrm{b} 5: 5,4: 6,3: 7$ and fluorescence treatment.

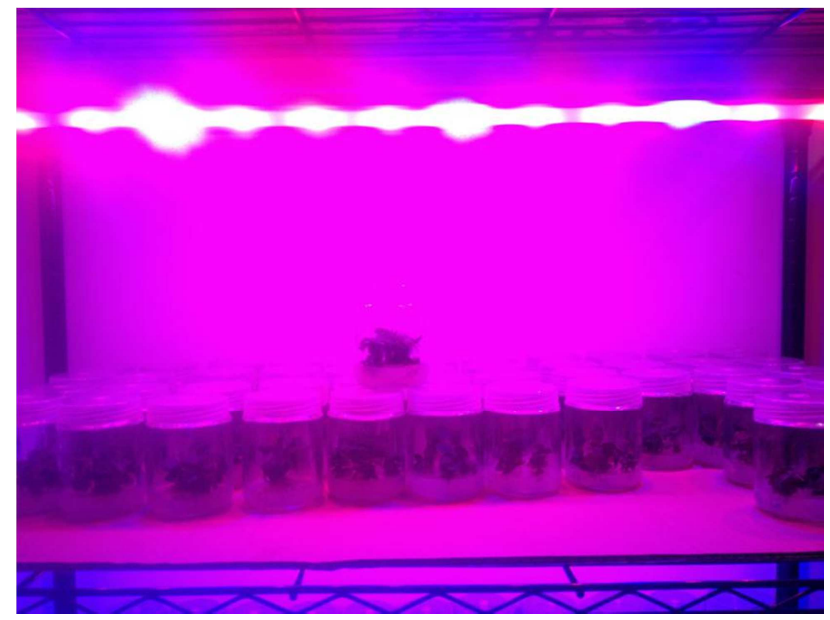

Figure 3. In $L E D r / b$ 6:4 light treatment.

Table 3. Treatment of rooting with different light quality.

\begin{tabular}{llllll}
\hline Grouping & \multirow{50\%}{*}{ rooting time } & 45 days & & & \\
\cline { 3 - 6 } experiment & of seedlings(day) & Average rooting rate (\%) & Root growth situation & Main root length(cm) & Seedling height(cm) \\
\hline Fluorescent lamp & 32 & 75 & Robust & 3.51 & 3.74 \\
LED r/b 5: 5 & 16 & 100 & Robust & 5.62 & 5.95 \\
LED r/b 4: 6 & 17 & 100 & Robust & 5.45 & 5.81 \\
LED r/b 3: 7 & 20 & 100 & Robust & 5.13 & 5.52 \\
LED r/b 6: 4 & 16 & 100 & Robust & 5.97 & 6.38 \\
LED r/b 7: 3 & 15 & 100 & Robust & 5.81 & 6.14 \\
\hline
\end{tabular}




\section{Conclusion}

The results showed that, in the same conditions of apple root-stock"JM7"tissue culture (same culture mediums, $21 \pm 1{ }^{\circ} \mathrm{C}$ temperature and 12 hours light, 12 hours dark), the LED lights were better than the fluorescent light source for whole culture process, the germination, proliferation, differentiation, and rooting were all better. Overall, LED treatments were excellent by $10 \%$ than fluorescent light. When the LED $\mathrm{r} / \mathrm{b}$ was $5: 5$, it was best for the germination culture stage. When the LED $\mathrm{r} / \mathrm{b}$ was $6: 4$, it was best for the proliferation, the differentiation and the rooting stage, on the 45 days of the proliferation and differentiation, the seedling height reached $4.15 \mathrm{~cm}$;on the 45 days of rooting stage, the seedling height reached $6.38 \mathrm{~cm}$, the root growth potential were strong, the length of the main root was $5.97 \mathrm{~cm}$. Followed by LED r/b 7:3, 5:5, 4:6, 3:7, then the fluorescence lamp. So we think that the LED light should be used in the plant tissue culture, it could get more quantity and stronger plants, saved $10 \%$ cost of whole tissue culture, and saved the culture time about 10 days of all.

\section{Discussion}

In the past six years, LED light source had been used in plant factories and plant tissue culture of horticultural. LED lights were used to the tissue culture of flowers, vegetables and some herbaceous fruits, but not used to the woody fruit. The effect of LED was better than the traditional light source such as tomato [7, 8], strawberry [9], pitaya fruit [10] and so on. Strawberry studies had shown that $70 \%$ LED red light + $30 \%$ LED blue light irradiation, the leaf number, root number and root length were better and good growth in the soil [11].

The results of this experiment showed that LED light source were better than fluorescent lamp at apple root-stock "JM7"tissue culture, got more quantity of plants and more stronger plants, saved $10 \%$ cost of whole tissue culture, and saved the culture time about 10 days of all. The combination of LED red and blue lights were superior to traditional fluorescent lamp. The combination of LED 50\% red light and $50 \%$ blue light was the best effect on the sprouting for "JM7", the height of seedling were $1.84 \mathrm{~cm}$ and 10 leaves on 50 days of cultivation. The combination of LED $60 \%$ red and $40 \%$ blue light was best effect on the differentiation, development and rooting of tissue culture seedlings, the height of seedling was $4.15 \mathrm{~cm}$ on 45 days of proliferation and the main-root length was $5.97 \mathrm{~cm}$, and the height of seedling was $6.38 \mathrm{~cm}$ on 45 days of rooting stage. Followed by LED 70\% red and 30\% blue light, then LED $50 \%$ red and $50 \%$ blue light.

In this experiment, only the germination time, germination rate and the number of seedling height and roots at different stages were compared with traditional fluorescent lamp. All these things showed that the LED light should be used in the future of plant tissue culture. But we just did these experiments in laboratory, we were not sure if these plants moved to the soil, could they adapt well to the natural environment? So the effect of different LED combinations on the subsequent growth of apple root-stock "JM7"seedlings need more study.

\section{References}

[1] Briand CH, Hicks GS (1989). Micropropagation of the cold-hardy apple rootstock KSC-3: a morphological analysis. Can J Plant Sci, 69: 555-564

[2] Kermani MJ, Hosseini ZS, Habashi AA (2009). A refined tissue culture medium for in vitro proliferation of apple roots-tocks. Acta Hort (ISHS), 829: 313-318

[3] Sicurani M, Piccioni E, Standardi A (2001). Micropropagation and preparation of synthetic seed in M. 26 apple rootstock I: attempts towards saving labor in the production of adventitious shoot tips suitable for encapsulation. Plant Cell Tiss Organ Cult, 66: $207-216$

[4] Yaseen M, Ahmad T, Abbasi NA, Hafiz IA (2009). Assessment of apple rootstocks M9 and M26 for in vitro rooting potential using different carbon sources. Pak J Bot, 41 (2): 769-781

[5] Wenke Liu, Qichang Yang, lingling Wei, LED light source and its horticultural application[M], Agricultural Science and Technology Press of China, 2012

[6] Tissue culture of Apple Dwarf rootstock 'JM7' and its adventitious shoot regeneration in vitro, Plant Physiology Journal 2014, 50 (6): 779-78

[7] Liu X. Y., Chang T. T., Guo S. R., et al. Effect of different light quality of LED on growth and photosynthetic character in cherry tomato seedling. Acta Horticulturae, 2011, 907: 325-330

[8] Yanagi T., Okamoto K., Takita S. Effect of blue and red light intensity on photosynthetic rate of strawberry leaves. Acta Horticultruae, 1996, 440: 371-376

[9] Jao R. C., Lai C. C., Fang W., et al. Effects of red light on the growth of Zantedeschia plant lets in vitro and tuber formation using light-emitting diodes. HorScience, 2005, 40(2): 436-438

[10] Wenjing Huang, Guangzhu Yang, Liping Zheng, Jun Ma, Effects of different light quality on growth and development of Pitaya tissue culture seedlings, China Fruits, 2014, (4)

[11] Rueychi J., Wei F. Growth of potato plantlets in vitro is different when provided concurrent versus alternating blue and red light photoperiods. HortScience, 2004, 39(2): 380-382 